\title{
PRODUÇÕES AUDIOVISUAIS CANADENSES E BRASILEIRAS: UMA ANÁLISE DE SOM \& FÚRIA
}

AUDIOVISUAL PRODUCTIONS CANADIAN AND

BRAZILIAN: ANALYSIS OF

"SOM E FÚRIA"

MURILO LUIZ FERREIRA

Autor: Mestrando em Comunicação, Cultura e Cidadania pela Universidade Federal de Goiás - FACOMB. Linha de Pesquisa: Mídia e Cultura.

E-mail: murilofeheira@gmail.com

Goiamérico Felício C. dos SANtos

Co-autor: Prof. ${ }^{\circ}$ Dr. do Curso Comunicação Social da FACOMB-UFG, email: goiamerico@gmail.com

\section{RESUMO}

Esse artigo se propõe a fazer uma análise para identificar as diferenças e as aproximações entre as produções audiovisuais canadenses e brasileiras para a TV. Para isso serão analisados os códigos nãoespecíficos: iluminação, figurino, cenário e cor para exemplificar que tudo o que é mostrado na tela tem um sentido e, na maioria das vezes uma segunda significação que só aparece através da reflexão. Com base na análise dos códigos não-específicos, este artigo analisa o primeiro episódio da minissérie Som\&Fúria, transmitida pela Rede Globo de Televisão e a minissérie canadense Slings\&Arrows, transmitida The Movie Network.

Palavras-chave: Produções audiovisuais, Minissérie, Som\&Fúria, Slings\&Arrows

\section{ABSTRACT}

This paper aims at analyzing and identifying the differences and similarities between the Canadian broadcast productions and the Brazilian ones. Then, it will consider the non-specific codes: lighting, costumes, set design and color to illustrate that everything that is shown

1 Este artigo, neste momento, não se propõe a tratar das estruturas das narrativas cinematográficas e televisuais. Este artigo não tratará do código não-específico diálogo, pois para isso é necessária uma análise de discurso mais aprofundada. on the screen has a meaning and, in most of the cases, this second meaning appears only through reflection. Based on the analysis of non-specific codes, this article examines the first episode of the Brazilian soap opera Som\&Fúria, broadcasted by the Globo channel, and the Canadian soap opera Slings\&Arrows, broadcasted by The Movie Network.

Keywords: Broadcast Productions, Soap Opera, Som\&Fúria, Slings\&Arrows 


\section{Imagem, som e fúria na tv}

Para analisar uma produção audiovisual, independente de qual o seu país de origem, é necessário situar essa produção dentro do meio que ela está sendo veiculada. Este artigo se propõe a fazer uma análise da minissérie Som \& Fúria, veiculada no Brasil pela Rede Globo de Televisão, no ano de 2009, e esta, por sua vez, é uma adaptação da minissérie canadense Slings \& Arrows, transmitida pela The Movie Network, no ano de 2003. Então, o objeto de análise está inserido no meio televisão, e se faz necessário tratar da linguagem televisual e o formato minissérie antes de qualquer análise de outros aspectos relevantes.

A televisão é o resultado da junção entre tecnologia, comunicação e arte. Com o advento da tecnologia a partir da década de 1940, com a necessidade de se desenvolver um meio que atingisse uma maior parcela da população de uma só vez, comunicar abertamente com o público e ao mesmo tempo oferecer um acesso maior a forma de artes, fizeram com que se criasse a televisão.

Com o passar dos anos, com o advento da tecnologia e com a produção e o consumo em massa da televisão, houve uma crescente necessidade de se desenvolver uma linguagem própria da TV. Mas pensar em uma linguagem para a televisão é ao mesmo tempo pensar na literatura, nas artes plásticas, no rádio, no folhetim, no teatro e no cinema. Este último é o que mais se aproxima da TV em termos narrativos e estruturais.

Mas conceituar a linguagem televisiva não é algo fácil. HOINEFF (1996, p. 85) fala que a busca de uma linguagem essencialmente televisiva esbarra na evidência de que a maior parte da programação veiculada tende a incorporar ou incorpora formas alheias ou até mesmo transmite manifestações artísticas já prontas.

No primeiro caso figura uma ampla coleção de quase tudo o que a televisão apresenta, desde telenovela (que incorporam formas do teatro e do cinema) até shows de variedades, cuja natureza básica é mais do que óbvia. No segundo estão os filmes, ou as transmissões esportivas, muito significativamente os grandes campeões de interesse popular. Em outras palavras, o que o telespectador mais gosta na televisão nada tem a ver com a criação televisiva. Mesmo os filmes feitos especialmente para a televisão em nada diferem, ao nível da linguagem, dos filmes narrativos convencionais; e, qualquer que seja o tratamento dado a uma transmissão esportiva, o que importa mesmo é o evento esportivo em si. Alguma coisa está errada, ou com o telespectador ou com a televisão. E é improvável que seja com o primeiro (HOINEFF, 1996, p.86-87).

O mosaico que forma a TV começa com a literatura, pois foi desse meio que a televisão aprendeu como narrar. Com o cinema ela buscou as técnicas de montagem, movimento de câmera, junção do som com a imagem, a utilização e apropriação dos elementos fílmicos específicos e não-específicos, além da forma de narrar através de imagens. $\mathrm{O}$ 
enquadramento utilizado pela TV fica por conta da herança das artes plásticas e do rádio, e dos folhetins literários a TV utilizou os ganchos e as interrupções. Já por volta da década de 1980, a linguagem publicitária passa a tomar conta dos intervalos dos programas e o uso em excesso da computação gráfica e do movimento exarcebado da câmera vêm com a pioneira MTV americana e passam a ser incorporados pelas demais redes do mundo.

Com essa junção de linguagens, a televisão pode ser considerada uma linguagem híbrida. BALOGH (2002, p. 50) define como linguagem híbrida a que um mesmo produto, em um mesmo programa, seja ele ficcional ou não, encontra-se diversas formas de arte.

\section{0 público se identifica e consagra a televisão}

Encontrar um ponto em comum entre as diversas linguagens que compõe o mosaico da linguagem da televisão é algo que se faz necessário para o entendimento de seu sucesso com a população. A narrativa, principalmente a narrativa de ficção, pode ser considerada o ponto de intersecção entre as diversas linguagens, e isso fez com que culminasse na linguagem híbrida da TV.

A narrativa ficcional herdada da literatura e dos folhetins literários e também a narrativa através de imagens herdada do cinema, podem ser consideradas as responsáveis pelo sucesso da televisão, principalmente em suas obras ficcionais.

Refletindo sobre a TV brasi- leira, não é difícil constatar que a maior parte de sua programação é composta de telejornais, filmes e, principalmente, programas de ficção. Essa ficção é uma ficção intervinda do real, ou seja, a televisão proporciona ao telespectador acompanhar o dia a dia dos personagens e também criar certa empatia e intimidade para e com ela.

Os personagens, as tramas, os cenários, passam a fazer parte do cotidiano das pessoas e também há de ser algo muito próximo a eles, como parte de seu convívio pessoal. Não é incomum o assunto das obras ficcionais transmitidas pela TV dominar uma roda de discussão, seja em casa, no trabalho e até nos momentos de lazer.

Essa relação intensa entre telespectador com a ficção televisiva tende a mostrar que a narrativa é responsável pelo êxito adquirido pela TV. Da mesma forma que o cinema buscou na literatura as suas estruturas para narrar, a televisão também buscou, mas de uma forma mais complementar, já que as suas fontes de aprendizado narrativo vieram das estruturas literárias e da linguagem cinematográfica.

A narrativa na ficção televisual abriga estruturas antigas, já consagradas em outras artes, que convivem com formas novas e são revitalizadas por novos modos de recepção e de veiculação. Os relatos são veiculados de modos descontínuos, interrompidos pelos comerciais. A fragmentação representa outra marca própria do mundo contemporâneo, ao qual as estruturas narrativas antigas se adaptam (BALOGH, 2002, p.52). 
A ficção na TV, com a sua forma de contar as histórias, utilizou experiências bem sucedidas do teatro e do cinema, lhes acrescentou o rádio e também não se esqueceu da forma da narrativa literária. Mais uma vez, a televisão utiliza outros meios para formar o seu próprio meio.

Tudo isso junto, teatro, narrativa, cinema, rádio e mais alguma coisa peculiar, redundou nas histórias televisadas, cada vez mais atraentes, na medida em que veiculam um conteúdo intencionalmente simples, tornando interessante pela utilização de técnicas mais sofisticadas e, ainda, de atores cada vez mais mistificados e idolatrados (PALLOTTINI, 1998, p.24).

Essas narrativas representam um micro-universo. Esse microuniverso é constituído de valores e conceitos da cultura em que ela está inserida. Então a narrativa televisiva pode ser um reflexo da cultura e dos valores dos seus telespectadores.

Essa forma de narrar na televisão faz com que se forme um discurso ficcional. Não é um discurso único, onde todos os programas ficcionais da TV seguem o mesmo padrão, pelo contrário, cada gênero ficcional apresenta um discurso diferente.

O consumo e a recepção da mensagem da televisão ocorrem em momentos distintos, não são idênticos, mas formam um todo dentro do processo de reforçar ideologias da sociedade. Os estudos culturais se propõem a ter uma visão nova e oposta aos conceitos da recepção da mensagem da TV. Para os culturalistas, diferentemente dos frankfurtianos, o discurso é interpretado, não há mensagem direta e nunca houve passividade do receptor. Essa visão contraria o que foi proposto e defendido por Adorno e se torna um divisor de águas em relação à interpretação das mensagens, quando o receptor passa a ter um papel ativo.

Segundo Hall (2003, p. 368) "o consumo ou a recepção da mensagem da televisão é, assim, também ela mesma um momento do processo de produção no seu sentido mais amplo, embora este último seja 'predominante' porque é 'o ponto de partida para a concretização' da mensagem".

Antes que essa mensagem possa ter um "efeito" (qualquer que seja sua definição), satisfaça uma "necessidade" ou tenha um "uso", deve primeiro ser apropriada como um discurso significativo e ser significativamente decodificada. É esse conjunto de significados decodificados que "tem um efeito", influencia, entretém, instrui ou persuade, com conseqüências perceptivas, cognitivas, emocionais, ideológicas ou comportamentais muito complexas (HALL, 2003, p. 369).

Para que a mensagem da televisão atinja plenamente o seu objetivo, é preciso que os significados que ela transmite sejam plenamente decodificados pelo público. O signo da televisão é um signo bastante complexo, pois, diferentemente dos signos linguísticos, ele é composto de dois tipos de discurso, o visual e o auditivo. E com base na teoria dos signos desenvolvida por Peirce, o signo da TV é um signo icônico. 
Uma vez que o discurso visual traduz um mundo tridimensional em planos bidimensionais, ele não pode, é claro, ser o referente ou o conceito que significa. [...] A realidade existe fora da linguagem, mas é constantemente mediada pela linguagem ou através dela: e o que nós podemos saber e dizer tem de ser produzido no discurso e através dele. $O$ "conhecimento" discursivo é o produto não da transparente representação do "real" na linguagem, mas da articulação da linguagem em condições e relações reais (HALL, 2003, p. 370).

No campo do signo televisivo, o nível denotativo é visto com certos códigos bem fechados e complexos. Já o nível conotativo é um campo também limitado, mas mais aberto do que o primeiro. Isso se dá porque cada sociedade tem as suas ideologias sociais, culturais e políticas, que influenciam na constituição do campo conotativo para o signo televisão.

Os domínios dos "sentidos preferenciais" têm embutido toda a ordem social enquanto conjunto de significados, práticas e crenças: o conhecimento cotidiano das estruturas sociais, do "modo como as coisas funcionam para todos os propósitos práticos nesta cultura"; a ordem hierárquica do poder e dos interesses e a estrutura das legitimações, restrições e sanções. Por isso, para esclarecer um "mal-entendido" em relação ao nível conotativo, devemos nos referir (através de códigos) às ordenações da vida social, do poder político e econômico e da ideologia (HALL, 2003, p. $374-375$ ).

Para o sucesso de uma mensagem televisiva é necessário que o público consiga decodificar os códigos por ela apresentados. Se o telespectador não consegue reconhecer o que está sendo dito e mostrado, se a narrativa é complexa e apresenta uma nova linguagem, provavelmente a audiência não irá acompanhar o processo de decodificação que a mensagem se propõe.

A preocupação de "se aproximar do real" não é uma característica exclusiva da telenovela, ela é um traço mais geral da indústria cultural. Edgar Morin já havia observado que o star system inaugura na década de 30 uma tendência ao realismo que até hoje permanece nos filmes de Hollywood. [...] A tendência para o realismo constitui uma estratégia que se fundamenta na ideia de verossimilhança. Quando na estória a ser contada é introduzida uma série de signos e sinais "de realidade", isto tem por finalidade estabelecer uma ligação entre o que está sendo mostrado e certas situações da vida cotidiana (ORTIZ, 1991, p. 141).

\section{As ficções e seus gêneros}

Para criar toda essa identificação entre público e televisão, os programas transmitidos por ela foram segmentados e definidos em gêneros e formatos, sejam eles ficcionais ou não. 
$\mathrm{Na}$ maioria das vezes quando se fala em gênero ficcional na $\mathrm{TV}$, telenovela é o primeiro gênero a se destacar. A ficção na televisão não é feita somente por telenovela, por mais que seja o seu programa ficcional de maior destaque na televisão brasileira.

Dentre os diversos gêneros ficcionais existentes, há também diversas tipologias. PALLOTTINI (1998, p. 28) utiliza a de que os gêneros televisivos ficcionais são divididos em unitário, seriado, telenovela e minissérie.

O unitário é um gênero televisivo que conta uma historia na TV que é levada ao ar de uma só vez e que basta por si só. Sua estrutura conta com começo, meio e fim e se esgota com um único episódio.

O seriado é estruturado de tal forma que seus episódios são independentes, mas respeitam uma unidade relativa entre eles. É uma história que o seu episódio tem começo, meio e fim, mas que obedece a estrutura e a lógica da narrativa. Nos episódios de um seriado encontra-se uma mistura entre os episódios do unitário e o capítulo da telenovela.

A telenovela é uma história contada através de imagens televisivas, com diálogos e ações, com a existência de conflitos provisórios e definitivos. Os conflitos provisórios vão se resolvendo no decorrer da trama e os definitivos só são resolvidos nos últimos capítulos.

TÁVOLA (1996, p. 53) considera que a audiência influencia na trama da telenovela, por isso ela é considerada uma obra semi-aberta.

A característica de obra semiaberta da telenovela permite a participação semidemocratizante do público, passando a ser outras das atividades públicas na qual este consegue exercer seu direito de opinar. Para tal, contudo, é necessário que a tessitura interna dos conflitos da história não escape ou transcenda o seu universo conceitual (TÁVOLA, 1996, p. 53).

E por último, mas não menos importante, a minissérie. Que pode ser considerada uma telenovela curta, mas com as suas particularidades. A primeira é que a minissérie é uma obra fechada, ou seja, antes das gravações e bem antes de ir ao ar, a minissérie já foi totalmente escrita.

Elas formam um conjunto de produto audiovisual diferenciado. Contam com uma produção mais bem elaborada por contar com mais tempo para isso. Seus capítulos não são feitos em produção industrial, e sim com mais cuidado em seus detalhes, nas suas pesquisas. Cuidados esses que vão desde a escolha da história, passando pela seleção dos atores, do figurino, dos cenários. Isso tudo porque a minissérie conta com um público mais seleto e mais exigente. O telespectador busca nela um produto diferenciado da telenovela, principalmente em qualidade.

Trata-se do formato considerado como o mais completo do ponto de vista estrutural e o mais denso do ponto de vista dramatúrgico. Os roteiristas o reputam como sendo o "ponto alto" da produção ficcional brasileira. Como tal, o formato recorre frequentemente à adaptação de obras literárias nacio- 
nais consagradas como gênero preferencial (romances) (BALOGH, 2002, p. 96).

E com a crescente tirania dos índices de audiência, a minissérie goza de uma situação mais confortável do que a telenovela. Pois esta é uma obra fechada e já toda produzida, então ela não corre o risco de ter que ser alterada durante sua exibição por causa da aprovação ou não da trama pelo público.

Essa situação confortável pode também se tornar um problema para a minissérie, pois com isso ela corre o risco de cair no fracasso exatamente por não poder se modificar no momento em que está sendo levada ao ar. Pois se a minissérie não obtiver aprovação do telespectador, a emissora amargará prejuízos em relação aos anunciantes por causa da baixa audiência. Mas se o contrario ocorrer, a emissora passa a ter mais destaque por fazer de uma minissérie, produzida para um público seleto, um produto de audiovisual de grande sucesso.

Creio que a minissérie seria uma fórmula positiva de levar cultura ao nosso povo. É um formato novo; não tão novo, mas surgiu há pouco tempo, e possibilita não só ao autor, como também ao diretor e à produção, um produto mais bem acabado, justamente por possuir número menor de capítulos - em torno de 20 - e tempo maior para a sua realização. Possibilita ao autor escrever, burilar e reescrever a sua obra. Esse mesmo texto, "Decadência", foi reescrito, por mim, umas três ou quatro vezes. [...] O produto foi muito trabalhado e tivemos uns seis meses para essa realização. Tempo que, geralmente, dispomos para escrever uma novela de cento e oitenta capitulos. [...] No entanto, a novela é que dá dinheiro e a minissérie, dizem, só dá prejuizos; é só um produto de luxo para, mais ou menos, "livrar a cara" da televisão (DIAS GOMES In: BALOGH, 2002, p. 124).

As minisséries, por serem mais elaboradas e terem um público mais seleto, são utilizadas para testar os limites do televisual e também inovar a linguagem e o discurso da TV. É um produto que mais se aproxima dos ideais tradicionais de artisticidade baseados na unidade estrutural do texto.

A linguagem televisiva conta com os seus diversos gêneros e também com o seu hibridismo que a faz se tornar uma linguagem que veio para juntar outras linguagens e também acrescentar a elas.

Colocar uma definição rígida para a linguagem da TV é desprezar os seus diversos gêneros e formatos. Tratar o unitário, o seriado, a minissérie e a telenovela da mesma forma, é ser incoerente. Cada um dos gêneros televisivos, isso se tratando dos gêneros ficcionais, sem levar em consideração o jornalístico, o humorístico, entre outros, tem as suas particularidades. Mas, ao mesmo tempo, esses gêneros ficcionais televisivos têm uma aproximação, principalmente em sua forma de narrar, já que um dos principais responsáveis para o sucesso da ficção na TV é a narrativa literária.

Essa base literária que a televisão conta, e também com a 
sua grande difusão, se tornando o veículo de maior alcance, se comparado ao alcance do rádio no início do século passado, a televisão se torna um grande instrumento de entretenimento, informação, difusão da cultura e formadora de opinião.

Seja proporcionando narrativas longas ou curtas, a ficção na TV passou a fazer parte do cotidiano de cada pessoa, e o aparelho de televisão passou a ser um produto essencial nos domicílios, não somente no Brasil, mas principalmente nele.

\section{Televisão, cinema e seus códigos}

Como já discutido anteriormente, a televisão tem o cinema como uma base de sua linguagem televisual. Por isso, este artigo utiliza a metodologia de análise da forma do cinema, para analisar o primeiro episódio de Som \& Fúria e Slings \& Arrows.

Como o cinema não é composto de língua e sim de códigos, isso o fez ter uma linguagem universal e que se pode aplicar em diversos outros formatos que narram com imagens. Mesmo com a variação entre um idioma e outro, uma cultura e outra, os códigos utilizados são os mesmos. MARTIN (1990, p. 56) fala de dois tipos de códigos, os específicos e os não-específicos.

Segundo AUMONT (2002, p. 196) os códigos específicos são os códigos que estão exclusivamente ligados a um tipo de material de representação. No cinema eles são de um número muito reduzido e estão ligados ao próprio material cinematográfico.
Considera-se como código específico do cinema os movimentos de câmera, a imagem em movimento e a montagem. O primeiro e o terceiro códigos, o cinema divide com a televisão, mas essa por sua vez tem uma de suas bases no cinema, por isso podese afirmar que a televisão tomou "emprestado" o movimento de câmera e a montagem do cinema.

Um exemplo tradicional de código especifico é o dos movimentos de câmera. Este diz respeito à totalidade do campo associativo vinculado às relações de fixidez e de mobilidade que podem intervir em um plano cinematográfico: a qualquer instante, a câmera pode permanecer fixa ou então produzir uma determinada trajetória (vertical, horizontal, circular). Cada um dos planos explicita uma escolha, isto é, a eliminação de todas as figuras não-presentes. Esse código é especifico porque necessita concretamente de mobilização da tecnologia cinematográfica (AUMONT, 2002, p. 196).

Os códigos não-específicos são os códigos representativos que não são exclusivamente de um tipo de material de representação. $\mathrm{Na}$ arte cinematográfica, assim como na televisão, são os códigos que não pertencem exclusivamente a elas, pois foram desenvolvidos por outros meios.

MARTIN (1990, p. 56) afirma que o cinema conta com um maior número de códigos nãoespecíficos do que de códigos específicos. Os principais códigos não-específicos são: iluminação, vestuário, cenário, cor e diálogos.

A iluminação é um fator deci- 
sivo para a criação da atmosfera do filme. É um código de difícil análise e que passa muitas vezes despercebido pelo espectador. Isso tudo não desabilita a iluminação de sua grande importância dentro da arte cinematográfica. Ela é utilizada para criar a atmosfera necessária para o desenvolvimento da narrativa. A iluminação é um código que o cinema compartilha com o teatro, TV, fotografia e também com as artes plásticas.

O vestuário não é um código artístico isolado, ele deve ser considerado junto com a direção, a fotografia e os cenários. Dependendo de sua utilização, ele pode aumentar ou diminuir o efeito presente na tela. No cinema, assim como na televisão, pode-se definir dois tipos de vestuários: os realistas, que estão de acordo com a realidade da narrativa; e os para-realistas, que são a estilização dos figurinos de época e os simbólicos, que têm a missão de simbolizar os seus caracteres.

No cinema o cenário compreende as paisagens naturais ou as construções humanas. Os cenários podem ser interiores e exteriores. Tanto os cenários interiores quanto os exteriores podem ser reais ou construídos. Quando se fala em cenários construídos, se toma a ideia de um cenário construído em um estúdio, mas nem sempre essa concepção é a correta. Podese construir cenários ao ar livre, dependendo da necessidade que a narrativa impõe.

MARTIN (1990, p. 63-64) define três tipos de cenários: realista, impressionista e expressionista. $\mathrm{O}$ cenário realista significa exatamente aquilo que ele é, sem nenhuma outra implicação, além disso; o cenário impressio- nista é escolhido de acordo com a psicologia da ação, reflete os dramas dos personagens e é um cenário natural; já o cenário expressionista é basicamente um cenário artificial que visa sugerir uma impressão plástica que coincida com a dominante psicológica da ação.

E por fim, a cor. Uma qualidade natural dos seres humanos que é ressaltada na narrativa com imagens. Tudo o que se vê tem uma cor. Esse trabalho de cor atinge um nível psicológico de seu entendimento. Depois do advento dos estudos da psicologia das cores, os diretores passaram a tratar esse código não-específico de uma forma mais séria, levando em conta as concepções psicológicas de como cada cor atinge o público.

Para a análise do objeto de estudo deste artigo, serão utilizados somente os códigos não-específicos discutido acima, pois eles dão uma noção clara de que tudo o que é mostrado na tela tem um sentido e, na maioria das vezes uma segunda significação que só aparece através da reflexão. Uma análise em conjunto dos dois episódios - original, Slings \& Arro$w s$, e adaptação brasileira, Som \& Fúria - buscará os pontos em comum e divergentes entre o original e a adaptação.

\section{Fúria slings \& som arrows}

Som \& Fúria e Slings \& Arrows narram a história de dois grupos de teatro, um rico e um pobre, que estão desenvolvendo peças de Shakespeare. A história desses dois grupos se cruza pelos três personagens principais, $\mathrm{El}$ - 
len, Dante e Oliveira. Uma tragédia do passado acabou separando esse trio. Dante, hoje, cuida da companhia de teatro pobre, enquanto Oliveira é um diretor em decadência do grupo rico. Uma tragédia, a morte de Oliveira, e o seu retorno como um fantasma que atormenta Dante, acabam fazendo com que o grupo se una novamente para recriarem a tão traumática peça de MacBeth.

A direção geral no original é feita por Bob Martin e a adaptação brasileira ficou a cargo do diretor Fernando Meirelles. O principal foco da minissérie é tratar dos conflitos internos dos personagens e tendo como pano de fundo a decadência do teatro, uma grande expressão artística que padece de recursos para a realização de grandes espetáculos.

Com esse aspecto já se pode identificar a semelhança entre a minissérie canadense e a brasileira, ambas retratam a batalha dos diretores para captar recursos públicos e privados, e a falta de investimentos na cultura.

Já em relação aos códigos nãoespecíficos da minissérie, pode-se identificar um maior número de semelhanças do que diferenças entre o original e a adaptação. Seguindo a linha metodológica proposta por MARTIN (1990, p. 56), o primeiro elemento a ser analisado é o da iluminação.

Como já discutido acima, a iluminação serve para criar a atmosfera, e é um fator decisivo na composição da narrativa. Segundo LINDGREN (1963, apud: MARTIN, 1990, p. 57), "a iluminação serve para definir e modelar os contornos e planos dos objetos, para criar a impressão de profundidade espacial, para produzir uma atmosfera emocional e mesmo certos efeitos dramáticos."

Em Slings \& Arrows, a iluminação utilizada é uma iluminação mais clara e objetiva, criando assim uma grande profundidade de campo. A atmosfera emocional que se cria com essa iluminação é que os personagens se encontram em estado de decadência, mas eles ainda tentam superar essas adversidades e fazerem sucesso novamente.

Já em Som \& Fúria, Fernando Meirelles e o diretor de fotografia, Adriano Goldman optaram por uma iluminação mais escura, com pouca profundidade de campo, criando assim uma atmosfera mais densa, que condiz com a situação psicológica dos personagens envolvidos na trama.

O segundo código não-específico é em relação ao vestuário ou figurino. O figurino utilizado em ambas as minisséries, são figurinos realistas e simbólicos. Realistas porque eles condizem com a época atual, por mais que o tempo seja subjetivo, mas os elementos em cena permitem a identificação com o tempo atual. E são simbólicos, pois permitem associar o figurino com a personalidade e os efeitos psicológicos de cada personagem.

O personagem principal Dante: um personagem que sempre usa roupas escuras e soltas, simbolizando um personagem totalmente descompromissado com a sua aparência e que passa por um momento conturbado, no qual tudo é incerteza e desorganização na sua vida, começando pelas roupas que veste.

Num filme o vestuário não é jamais um elemento artístico iso- 
lado. Deve-se considerá-lo em relação a um certo estilo de direção, cujo efeito pode aumentar ou diminuir. Ele se destacará dos diferentes cenários para pôr em evidência gestos e atitudes dos personagens, conforme sua postura e expressão. Por harmonia ou por contraste, deixará sua marca no grupamento dos atores e no conjunto de um plano. Enfim, sob esta ou aquela iluminação, poderá ser modelado - realçado pela luz ou apagado pelas sombras (EISNER, Lotte. Apud: MARTIN, 1990, p. 61).

Outro elemento que ajuda na composição da narrativa, juntamente com a iluminação e o figurino, é o cenário. Os cenários identificados no primeiro episódio de Slings \& Arrows e de Som \& Fúria, são realistas, pois mostram exatamente aquilo que são.

Logo na primeira sequência da minissérie, o telespectador é apresentado ao cenário da companhia de teatro pobre comandada pelo personagem Dante. É um galpão velho, sujo, que passa exatamente a sensação de decadência da companhia. E um outro item que compõe essa atmosfera de decadência é quando a câmera focaliza o nome do teatro, Teatro Sans Argent (Teatro Sem Dinheiro).

Após a sequência nesse teatro velho, o telespectador se encontra com a grandeza de um teatro tradicional, grandes escadarias, um palco enorme e centenas de cadeiras para o público, ou seja, um teatro onde se tem todo o suporte para desenvolver uma peça. Um contraste claro entre as duas companhias de teatro.

O último código de análi- se proposto por esse artigo, que ajuda a formar a significação do conjunto iluminação, figurino e cenário, é a cor. A cor não precisa, necessariamente, ser realista, ela precisa ajudar a compor as implicações psicológicas e dramáticas da narrativa, usando as suas tonalidades quentes ou frias.

Em Slings \& Arrows encontra-se uma predominância de cores quentes. Tanto no cenário, figurino e iluminação, as tonalidades quentes prevalecem. Isso fez com que a cor fosse um contrapeso com as angústias e os conflitos dos personagens.

Já em Som \& Fúria, a tonalidade predominante é de cor fria. Os diretores, de fotografia e geral, optam por utilizar cores mais frias para ajudar a compor as implicações psicológicas que os personagens sentem. Um outro fator que se pode analisar é que as minisséries brasileiras, segundo BALLOGH (2002, p. 127), se tornaram um espaço para testar os limites da televisão, tentando inovar na sua linguagem ou de ultrapassar as próprias concepções da linguagem audiovisual. E Som \& Fúria veio com esse propósito, em um primeiro momento, por utilizar de película para a sua filmagem, e também do uso cores frias, que é um outro ponto desse novo teste de linguagem, já que telenovelas, minisséries e seriados brasileiros têm o costume de utilizar cores quentes, com iluminação direta.

\section{O fim do começo}

Iluminação, figurino, cenário e cor são os quatro princi- 
pais códigos que se encontram em todas as produções audiovisuais. Esses códigos não-específicos analisados no primeiro episódio de Slings \& Arrows e de Som \& Fúria, fazem com que se chegue à conclusão de que, a união de tudo que está sendo mostrado na tela forma um todo, uma grande significação para compor a narrativa.

Uma produção audiovisual deve estar coerente com a realidade sócio-cultural de uma sociedade. Como esses códigos não-específicos são elementos universais, permite que essa análise seja realizada com produções de qualquer país.

Os pontos em comum entre o original canadense e a adaptação brasileira, se restringem aos códigos específicos, isso permite com que se visualize que há uma relação próxima entre as técnicas utilizadas nas produções audiovisuais do Canadá e do Brasil.

Em relação aos pontos divergentes entre Slings \& Arrows e Som \& Fúria, são os pontos que variam de acordo com as implicações culturais dos telespectadores canadenses e brasileiros. Deixando evidente que as produções audiovisuais, por mais que utilizem de técnicas semelhantes, buscam utilizar de elementos verossímeis que criem uma maior identificação com o público-alvo de seu país.

\section{Referências}

AUMONT, Jacques. A estética do filme. São Paulo: Papirus, 2002.

BALOGH, Anna Maria. O discurso ficcional na $T V$ : sedução e sonho em doses homeopáticas. São Paulo: USP, 2002.

HALL, Stuart. Da diáspora: identidades e mediações culturais. Belo Horizonte: Editora UFMG, 2003.

HOINEFF, Nelson. A nova televisão: desmassificação e o impasse das grandes redes. Rio de Janeiro: Relume Dumara, 1996.

MARTIN, Marcel. A linguagem cinematográfica. São Paulo: Brasiliense, 1990.

ORTIZ, Renato; BORELLI, Silvia Helena Simões; RAMOS, José Mario Ortiz. Telenovela: história e produção. São Paulo: Editora Brasiliense, 1991.

PALLOTTINI, Renata. Dramaturgia de televisão. São Paulo: Editora Moderna, 1998.

TÁVOLA, Artur da. A telenovela brasileira: história, análise e conteúdo. Rio de Janeiro: Editora Globo, 1996. 